\title{
Fundação Estatal no Serviço Público de Saúde: INCONSISTÊNCIAS E INCONSTITUCIONALIDADES
}

\author{
STATE FOUNDATION ON HEALTH PUBLIC SERVICE: \\ INCONSISTENCIES AND UNCONSTITUCIONALITIES
}

Marlon Alberto Weichert(*)

\section{RESUMO}

O artigo aborda os aspectos constitucionais da proposta do governo federal brasileiro de instituição de uma nova espécie de pessoa jurídica para a prestação de serviços públicos de saúde: as fundações estatais. Utilizouse o método lógico-sistemático de pesquisa, com uso de fontes bibliográficas e jurisprudenciais. O projeto governamental de criar fundações estatais em saúde é positivo ao pretender a retomada pela administração pública da gestão de serviços públicos que estão sendo geridos pela iniciativa privada. Porém, alguns elementos essenciais do modelo jurídico adotado são incompatíveis com a Constituição. A fundação estatal não poderá atuar na prestação do serviço público de saúde em caráter permanente. Sua atuação deverá ser estritamente na realização de atividades econômicas. A criação das fundações estatais em saúde significará também um retrocesso na proteção do patrimônio público e social.

\section{Palavras-chave}

Direito à Saúde; Fundação Pública; Recursos Humanos; Sistema Público de Saúde Pública.

(*) Mestre em Direito Constitucional pela Pontifícia Universidade Católica de São Paulo, Especialista em Direito Sanitário pela Universidade de Brasília, Procurador Regional da República e Membro do Conselho de Bioética do Instituto Nacional do Câncer — INCA. E-mail:<mweichert@prr3.mpf.gov.br>. Recebido em 3.9.08. Aprovado em 15.10.08. 


\begin{abstract}
The article analyses the constitucional aspects of the Brazilian federal government proposal of creating a new kind of legal entity for public health services: the state foundation. The research followed the logical and sistematical method, using bibliographic and case studies as sources. The governamental project is positive since it has the intention of returning to the public management some public services that were transferred to the private sector in the past. However, in some essencial issues, the model is incompatible with the Brazilian Constitution. The state foundation will not be able to run public health services on a permanent basis. Its operation should be strictly within economic activities. The creation of the state foundation on health will also represent a regression to the protection of the social and public patrimony.
\end{abstract}

\title{
Keywords
} Health.

Human Resources; Public Foundation; Public Health System; Right to

\section{INTRODUÇÃO}

O governo federal apresentou ao Congresso Nacional o Projeto de Lei Complementar n. 92/2007, para regulamentar o inciso XIX, do art. 37, da Constituição Federal, parte final, definindo áreas de atuação para fundações instituídas pelo poder público.

Segundo o projeto de lei complementar, por meio de lei ordinária os entes federativos poderão autorizar a instituição de "fundação sem fins lucrativos, integrante da administração pública indireta, com personalidade de pessoa jurídica de (...) direito privado", para desempenhar atividades estatais que não sejam exclusivas do Estado, inclusive na área da saúde. Essas entidades estão sendo denominadas fundações estatais.

Embora o projeto de lei complementar não traga outros elementos sobre o perfil das fundações estatais, o governo promoveu diversas discussões para apresentar e aperfeiçoar a proposta. A partir desses encontros, foi possível compreender de forma mais ampla o projeto de implementação das fundações estatais.

Este artigo dedicar-se-á a analisar a proposta das fundações estatais em saúde, adotando como premissa o perfil jurídico desenhado no PLC $\mathrm{n}$. 92/2007 e o modelo operacional apresentado pelo governo federal ${ }^{(1)}$.

(1) Baseamo-nos nos seguintes textos apresentados pelo governo federal: BRASIL. Ministério do Planejamento, Orçamento e Gestão. Projeto Fundação Estatal: principais aspectos. Brasília: MP, 2007; BRASIL. Secretaria de Gestão do Ministério do Planejamento, Orçamento e Gestão. Discursos e Palestras. In: Seminário Aspectos Jurídicos da Fundação Estatal. 2007. Brasília/DF. 


\section{A PROPOSTA DAS FUNDAÇÕES ESTATAIS}

O Sistema Único de Saúde deveria ser operado através de uma rede predominantemente pública de serviços. A contratação de serviços da iniciativa privada deveria ser pontual e temporária, apenas para suprir deficiências transitórias da administração pública. Escrevemos em oportunidade anterior:

Reconhecendo que a estrutura pública não seria suficiente para dar plena assistência à toda a população (especialmente pela herança de contratação de serviços privados no modelo do então INAMPS), a Constituição Federal permitiu a participação de entidades particulares no âmbito do Sistema Único de Saúde.

Essa participação deve se dar de forma complementar à rede pública, ou seja, somente pode haver contratação de serviços privados quando forem insuficientes as estruturas do Poder Público. A simples menção a uma participação complementar permite concluir que a Constituição concedeu primazia à execução do serviço público de saúde por uma rede própria dos entes federativos. Atendimento público através de serviços privados deve consistir exceção, tolerável apenas se e enquanto não disponibilizado diretamente pelo Poder Público. ${ }^{(2)}$

Entretanto, a realidade concreta é bem diferente. O SUS foi erguido a partir das ruínas do Instituto Nacional de Assistência Médica da Previdência Social (INAMPS), cuja lógica e estrutura funcional se baseavam na contratação de serviços privados de assistência à saúde. Antes do advento do SUS, o Poder Público pouco investiu em serviços próprios, tendo estimulado a iniciativa privada a constituir serviços de assistência médica que contavam com a garantia de serem contratados pela autarquia.

Com a implantação do SUS, o projeto constitucional era de reversão desse processo. O Estado deveria desenvolver atividades de promoção da saúde, inclusive de assistência curativa, com estruturas públicas ${ }^{(3)}$. A manutenção de contratos e convênios com os serviços privados que compunham a rede do INAMPS deveria ser paulatinamente revertida, na medida em que - Estado implantasse a sua própria rede de serviços. Anote-se que esse processo de "publicização" seria concomitante ao de descentralização. Isso porque até 1988 a responsabilidade pela assistência médica era predominantemente federal, dentro da estrutura da previdência social. O Sistema Único de Saúde, ao contrário, está pautado pela proposta de atribuição aos Municípios da assistência básica, e aos Estados do atendimento hospitalar

(2) WEICHERT, Marlon Alberto. Saúde e Federação na Constituição Brasileira. Rio de Janeiro: Lumen Juris, 2004. p. 199.

(3) Cf. AITH, Fernando. Curso de direito sanitário: a proteção do direito à saúde no Brasil. São Paulo: Quartier Latin, 2007. p. 351. 
complexo. Ou seja, dupla alteração no modelo até então vigente, mediante assunção pelos Municípios e Estados da prestação direta de serviços que eram prestados por meio de uma rede privada contratada pelo ente federal.

Entretanto, esse modelo nunca chegou a ser efetivamente implementado. Não só a descentralização ocorreu em ritmo lento(4), como poucos serviços públicos foram implementados para assumir o papel que era desempenhado pelos prestadores privados. As dificuldades financeiras e econômicas do Estado brasileiro e o advento de conceitos liberais e antagônicos à implementação do Estado Social impediram a execução desse modelo.

Ao contrário, por força da concepção político-econômica de redução do tamanho do Estado, vigente nos anos noventa, os governos optaram por transferir à sociedade civil a realização dos serviços relacionados à implementação dos direitos sociais, mediante financiamento público. O modelo de organizações sociais (OS), organizações da sociedade civil de interesse público (OSCIP) e fundações de apoio se alastrou pelo SUS. Em vários entes federativos, até mesmo serviços que eram prestados diretamente pelo Estado foram transferidos para pessoas jurídicas de direito privado. Em alguns casos, a gestão de redes de hospitais e postos de saúde foi integralmente repassada para entidades particulares, demitindo-se o Poder Público de uma das principais tarefas que a Constituição Ihe havia atribuído.

Além de inconstitucional, o repasse a particulares da atividade típica de Estado na saúde resultou, em vários casos: em desvio nas prioridades do SUS (a atividade preventiva é preterida pelos agentes particulares), na instituição de portas duplas de atendimento (SUS e planos de saúde, com prejuízo ao primeiro), na supressão do concurso público para acesso à carreira, em desvio de recursos, em falta de transparência etc. O modelo OS/OSCIP/Fundação de Apoio no SUS vem recebendo reiteradas críticas do Ministério Público e do Tribunal de Contas da União.

A proposta da instituição de fundações estatais visaria substituir o tal modelo de terceirização. Entidades públicas dotadas de maior agilidade de gestão tomariam o lugar das organizações não-governamentais na gestão de estruturas públicas do SUS. As fundações estatais permitiriam, pois, uma retomada pelo Poder Público da prestação direta dos serviços de saúde do SUS, em contraponto à fase de privatização que vigorou na década passada.

\section{Expõe o governo federal:}

Embora seja entidade de direito privado, a fundação estatal é essencialmente diferente das modalidades de entidades da sociedade civil que estabelecem relação de fomento e parceria com o Estado, tais como as organizações sociais

(4) Por responsabilidade não só da União, mas também dos Estados e Municípios que, em muitos casos, não demonstraram interessem nem competência em desempenhar essas funções. 
(OS), as organizações da sociedade civil de interesse público (OSCIP), os serviços sociais autônomos (SSA) e as fundações de apoio. Ela é administração pública: patrimônio público personalizado segundo as regras do direito privado para a prestação de serviços públicos. Seus agentes são empregados públicos, revestidos de responsabilidade pública. Quando o Poder Público institui uma fundação estatal para executar determinado serviço público ele mantém o processo decisional dentro do espaço público - dentro do próprio Estado, de forma diversa do que ocorre com o os modelos de OS, OSCIP e fundações de apoio. Isso porque o sistema de governança da fundação estatal é público e sua direção está sujeita às macro-orientações de governo e à política setorial que regem a ação da administração direta e indireta em seu setor de atuação, tais como as autarquias e as empresas estatais. É bom lembrar que as OS, OSCIP e fundações de apoio, assim como outras entidades de sociedade civil que mantêm relação de parceria com o Estado por via de contrato estatal de serviços, termo de parceria ou convênio, não integram a administração indireta. Não são supervisionadas e fiscalizadas pelos órgãos de controle da Administração. Sua gestão é privada, não se submetendo a normas de direito público. Seus empregados também não são públicos, podendo ser contratados sem concurso. Nelas, o que é objeto de fiscalização é a aplicação do recurso de origem pública e não sua gestão. O modelo de fundação estatal, em contraposição aos modelos de OS e OSCIP, é uma proposta de novo formato jurídicoinstitucional para a ação do Estado no campo social, dentro da Administração Pública, sem migrar a responsabilidade pela entrega de bens e serviços essenciais à população para o campo da iniciativa privada, por meio de parceria ou contratação. ${ }^{(5)}$

A fundação estatal prestaria serviços públicos, segundo o regime jurídico aplicável às entidades governamentais que atuam na atividade econômica, tais como as empresas públicas e as sociedades de economia mista. Um "regime administrativo mínimo"(6). Cada uma teria seu próprio corpo de profissionais, regidos pela CLT, contratados mediante concursos públicos e mantidos sem vínculo de estabilidade; o regime de licitações não seguiria o rigor da Lei n. 8.666/93, mas sim regulamentos próprios; a remuneração de seus funcionários e diretores não seguiria os tetos remuneratórios do Poder Público; a gestão financeira não se submeteria à Lei de Responsabilidade Fiscal.

Conforme exposição feita pelo Ministério do Planejamento, Orçamento e Gestão, as fundações estatais seriam, pois:

entidades sem fins lucrativos, com personalidade jurídica de direito privado, instituída pelo Poder Público, com autonomia gerencial, orçamentária e financeira, patrimônio próprio e receitas próprias, submetida à gestão dos órgãos de direção ou gerência, conforme dispuser o seu estatuto. Instituída em área não exclusiva de Estado e que não exijam o exercício do poder de autoridade:

(5) BRASIL. Ministério do Planejamento, Orçamento e Gestão. Projeto Fundação Estatal: principais aspectos, cit., p. 12-13, nota de rodapé 9.

(6) Id. Ibid., p. 14. 
educação, ciência e tecnologia, cultura, meio-ambiente, desporto, turismo, comunicação, previdência complementar, assistência social, saúde, dentre outras. Não é mantida pelo Poder Público: não integra o Orçamento Geral da União. Receitas constituídas pelas rendas da prestação de serviços ao Poder Público, do desenvolvimento de suas atividades e de doações. Não tem folha de pagamento paga pelo Orçamento Geral da União. Firma contrato de gestão com o Poder Público. Regime de pessoal: CLT. De acordo com a Lei n. 8.666/ 93, art. $1^{\circ}$ e 119, poderá editar regulamento próprio, devidamente publicado, ficando sujeita às disposições da lei, à semelhança do que ocorre com as sociedades de economia mista e empresas, para fins de licitação.(7)

Segundo foi divulgado, vislumbram-se dois campos iniciais para as fundações estatais em saúde, a depender do cenário que se deseja enfrentar. Uma primeira hipótese refere-se a hospitais ou outros grandes serviços que necessitam de autonomia administrativa e maior agilidade operacional. Vários são atualmente geridos, ou apoiados, por entidades privadas. Esses hospitais - integrantes da administração direta - seriam transformados em fundações estatais e dispensariam a interveniência das entidades privadas na sua administração. É principalmente o caso de hospitais universitários, dos hospitais federais no Rio de Janeiro ${ }^{(8)}$ e de diversos serviços estaduais e municipais. Com essa medida, seriam afastados os vícios decorrentes e inerentes ao uso de OS, OSCIP e fundações de apoio na gestão dos serviços públicos de saúde, bem como se tentaria superar as deficiências - em alguns casos crônicas - na assistência à saúde por essas unidades.

A segunda hipótese aventada consistiria na constituição de fundações estatais pelos Estados para prover recursos humanos a pequenos Municípios, que possuem dificuldade de contratação e retenção de profissionais. Nesse caso, a fundação estatal do Estado prestaria serviços ao Município que a contratasse, cedendo onerosamente mão-de-obra para a realização do atendimento à população. Estima-se que essa estrutura estimulará a permanência dos profissionais no SUS, pois será possível oferecer perspectivas de ascensão na carreira, inclusive com remoção entre Municípios.

\section{ANTECEDENTES: DEFICIÊNCIAS NO ATENDIMENTO REALIZADO PELO SUS}

Os dois campos de atuação previstos para as fundações estatais efetivamente reclamam iniciativas do Poder Público.

(7) BRASIL. Secretaria de Gestão do Ministério do Planejamento, Orçamento e Gestão. Discursos e Palestras, cit.

(8) Essa situação, por si só, é indicativa de descumprimento de preceitos do SUS. Em regra, a União Federal não deveria manter hospitais próprios, salvo se fossem de referência nacional, tais como o Instituto Nacional do Câncer e o Instituto Nacional de Traumatologia e Ortopedia. 
Hospitais e outros grandes serviços públicos de atenção à saúde não raramente pecam pela falta de eficiência. Uma das causas desse quadro é a desmotivação dos recursos humanos, provocando um baixo índice de comprometimento com o resultado e o destinatário dos serviços, ou seja, o usuário. Em que pese o enorme esforço de alguns servidores, verifica-se que parcela expressiva dos profissionais da rede pública não cumpre seus deveres funcionais, a começar pela observância da jornada de trabalho. Especialmente o corpo clínico dedica-se a múltiplas frentes de trabalho, militando não só no atendimento pelo SUS, mas também na concomitante prestação de serviços em caráter particular, em consultórios, clínicas e hospitais privados. Sem perspectivas de carreira, sem paradigmas positivos e ambicionando desenvolvimento profissional, os médicos da rede pública preterem suas obrigações no SUS pelas atividades que the conferem maior remuneração.

Parece-nos que a principal crise da rede de assistência do SUS é a de recursos humanos. O Poder Público muitas vezes é incapaz de motivar os profissionais de saúde a se dedicarem intensamente à prestação dos serviços públicos de saúde. Não só pela carência de um plano de carreira, mas também pelo exemplo negativo que dá no processo de escolha de diretores para os serviços de saúde. O padrão de seleção é a indicação política, com a outorga de privilégios aos que participam dos acordos e processos político-eleitorais, em detrimento daqueles que se dedicam à produção técnica e à busca de uma gestão estritamente profissional.

A contaminação dos órgãos diretivos pelas escolhas sem critério técnico acarreta, muitas vezes, a adoção de medidas administrativas desvinculadas dos planos de saúde (pois o compromisso do gestor é acima de tudo com o projeto do seu partido) e, eventualmente, desvio de recursos e outras práticas ilícitas.

Acresça-se, ainda, a crônica falta de controle sobre a gestão e a execução dos serviços, permitindo não só que profissionais descumpram escancaradamente seus compromissos funcionais (a começar pelo respeito à jornada de trabalho), como também propiciando a aplicação ineficiente de recursos materiais. Lembre-se, ademais, que os desvios de recursos na área da saúde - notadamente por malversação - são enormes, sem que se verifiquem inovações do Poder Público na prevenção desses ilícitos.

Por outro lado, Municípios de pequeno e médio porte - ou de localização mais remota - têm dificuldades para a contratação e a retenção dos recursos humanos. Esses entes federativos não possuem condições de oferecer perspectivas de carreira e de remuneração. Conseguem, no máximo, oferecer atrativos para a contratação, mas diante da restrita dimensão da sua rede própria e do papel que deve desempenhar no SUS (assistência primária), 
dificilmente logram reter em seus quadros os profissionais de saúde. Estes partem em busca de novos desafios e de maior projeção, conforme carreiras só disponíveis em centros urbanos de população mais numerosa.

As fundações estatais se destinariam, portanto, a enfrentar alguns desses problemas: reestatizar a gestão (excluindo organizações sociais e fundações de apoio), dinamizar a gestão de serviços de grande porte e permitir que Municípios tenham recursos humanos disponíveis, mediante uma carreira organizada no nível estadual, com ascensão intermunicipal, mas intraestadual.

O questionamento a ser feito reside, porém, na adequação da solução proposta, diante dos problemas que existem e devem ser atacados. Ou seja, é a proposta da fundação estatal em saúde compatível: (a) com os preceitos constitucionais que tratam da administração pública; e (b) com o Sistema Único de Saúde? Essa proposta é (c) apta a resolver os males que diz combater? É o que passaremos a analisar.

\section{PERFIL CONSTITUCIONAL DA FUNDAÇÃO ESTATAL}

A proposta aponta que a matriz constitucional das fundações estatais seria o disposto no art. 37, inciso XIX, com a redação dada pela Emenda Constitucional n. 19, de 1998, verbis:

XIX - somente por lei específica poderá ser criada autarquia e autorizada a instituição de empresa pública, de sociedade de economia mista e de fundação, cabendo à lei complementar, neste último caso, definir as áreas de sua atuação.

Segundo os autores da proposta, este dispositivo constitucional teria superado a discussão então existente sobre a possibilidade do Poder Público instituir fundações de direito privado. Isso porque, a redação original da Constituição de 1988 havia eliminado essa figura, ao igualar as fundações instituídas e mantidas pelo Poder Público às autarquias. O papel da Emenda Constitucional n. 19, nesse particular, teria sido autorizar o uso do regime de direito privado a fundações criadas pelo Estado.

Ainda que assim seja (a nosso ver a redação não é clara no sentido de ter instituído um novo tipo de entidade pública), o ponto nodal da questão é apurar se uma fundação que presta serviços públicos de saúde pode ser

regida sob o regime de direito privado.

A matéria é bastante tranquila no âmbito do Supremo Tribunal Federal, valendo destacar, dentre outros, o acórdão prolatado no Recurso Extraordinário n. 127.489-1/RJ:

RECURSO EXTRAORDINÁRIO. UNIVERSIDADE DO RIO DE JANEIRO. EXPEDIÇÃO DE DIPLOMA. CONDENAÇÃO. CONFLITO DE COMPETÊNCIA. 
NATUREZA JURIDICA DAS FUNDAÇÕES INSTITUIDDAS PELO PODER PÚBLICO. CONFLITO DE COMPETÊNCIA. ART. 109, I DA CONSTITUIÇÃO FEDERAL.

1. A Fundação Universidade do Rio de Janeiro tem natureza de fundação pública, pois assume a gestão de serviço estatal, sendo entidade mantida por recursos orçamentários sob a direção do Poder Público, e, portanto, integrante da Administração Indireta.

2. Conflito de competência entre a Justiça Comum e a Justiça Federal. Art. 109, I da Constituição Federal. Compete à Justiça Federal processar e julgar ação em que figure como parte fundação instituída pelo Poder Público Federal, uma vez que o tratamento dado às fundações federais é o mesmo deferido às autarquias.

2.1. Embora o art. 109, I da Constituição Federal não se refira expressamente às fundações, o entendimento desta Corte é no sentido de que a finalidade, a origem dos recursos e o regime administrativo de tutela absoluta a que, por lei, está sujeita a entidade, fazem dele espécie do gênero autarquia e, por isso, são jurisdicionadas à Justiça Federal, se instituídas pelo Governo Federal.

Recurso extraordinário conhecido e provido. (Rel. Min. MAURÍCIO CORRÊA, 2 ${ }^{a}$ Turma, v. u., DJ 6.3.98)

Com efeito, o que definirá a natureza jurídica da fundação não é a sua forma de constituição ou a denominação que lhe for dada, mas sim o serviço a ela afetado. Se desempenhar função de prestação de serviços típicos do Estado, parece claro que se trata de uma fundação de direito público, equivalente a uma autarquia. Com efeito, o fenômeno será de desconcentração de uma atividade estatal para uma pessoa jurídica específica, à qual é atribuída uma função que, originariamente, é do próprio Poder Público. Porém, se sua atividade for econômica, a fundação instituída pelo Poder Público poderá ser de direito privado. A fundação privada deve perseguir finalidades privadas.

Outras decisões do Supremo Tribunal Federal confirmam esse entendimento, tais como: (a) ADI n. 191-RS: "A distinção entre fundações públicas e privadas decorre da forma como foram criadas, da opção legal pelo regime jurídico a que se submetem, da titularidade de poderes e também da natureza dos serviços por elas prestados." (Rel. Min. Carmem Lucia); e (b) RE n. 381204-RS: "Sob a égide da Constituição anterior, o Plenário desta Corte, ao julgar o RE 101.126, assentou que 'as fundações instituídas pelo Poder Público, que assumem a gestão de serviço estatal e se submetem a regime administrativo previsto, nos Estados-membros, por leis estaduais são fundações de direito público, e, portanto, pessoas jurídicas de direito público'." (Rel. Min. Ellen Gracie).

No caso da fundação estatal em saúde, a possibilidade de revestir a natureza de pessoa jurídica de direito privado dependerá, portanto, da atividade que lhe for afetada. Não é possível afirmar, a priori, que todas as atividades 
são (in)compatíveis com esse modelo de pessoa jurídica instituída pelo Poder Público. Algumas atividades realizadas pelo Estado no âmbito da promoção à saúde podem, efetivamente, ser consideradas econômicas e, nessa hipótese, adequadas às fundações estatais de direito privado. Por exemplo, parece-nos que uma fundação estatal poderia se dedicar à produção de medicamentos, ou sua distribuição, ou mesmo comercialização a instituições privadas, realizando em todos esses casos atividades de natureza econômica, que também poderiam ser exercidas por sociedades de economia mista ou empresas públicas.

Entretanto, a prestação do serviço público de assistência à saúde da população através do SUS é atividade típica do Poder Público; é serviço público de relevância pública ${ }^{(9)}$, que não pode ser transformado em atividade econômica. Para essas atividades, o regime de direito privado não é passível de ser empregado.

Em suma, parece-nos que a prestação de serviços públicos de saúde é exclusiva de instituições estatais regidas pelo direito público, enquanto a realização de atividades econômicas pode ser afetada a pessoas jurídicas estatais de direito privado, tais como as sociedades de economia mista, as empresas públicas e, também, as novéis fundações.

Até o momento, este autor identificou perspectivas de serem instituídas fundações públicas com os dois propósitos acima indicados: (a) assumir a gestão e prestação integral de determinado serviço público; e (b) prestar serviços de cessão de recursos humanos a outros entes federativos.

É necessário, portanto, perquirir se prestarão serviços públicos e se serão mantidas pelo Poder Público. Caso positivo, terão natureza autárquica e não poderão ser constituídas sob o regime de direito privado. Na hipótese contrária, realizarão atividade econômica e podem revestir a condição de fundações de direito privado. A regra poderia, aliás, ser assim resumida: se a atividade puder ser atribuída a uma empresa pública ou sociedade de economia mista, também admitirá a fundação estatal de direito privado, pois, todas elas militam no mesmo campo.

O primeiro nicho operacional identificado - gestão de hospitais e outros serviços de atenção à saúde da população - parece-nos incompatível com a figura de uma fundação de direito privado.

Isso porque o próprio texto constitucional (arts. 198 e 199, § 1º) define que o serviço público de saúde deve ser prestado diretamente pelo Poder

(9) Sobre o conceito de relevância pública, vide: DALLARI, Sueli Gandolfi. O conceito constitucional de relevância pública. Brasília: Organização Panamericana de Saúde, 1992; WEICHERT, Marlon Alberto. A saúde como serviço de relevância pública e a ação civil pública em sua defesa. In: ROCHA, João Carlos de Carvalho et al. (Orgs.). Ação civil pública - 20 anos da Lei n. 7.347/85. Belo Horizonte: Del Rey, 2005. 
Público. Trata-se de um serviço público, a ser prestado pelo Estado, sem possibilidade de utilização das figuras clássicas da transferência de sua execução, via concessão ou permissão, a particulares.

Não se olvida que o art. 199, caput, da Lei Fundamental autoriza a participação da iniciativa privada na área da saúde. Entretanto, essa liberdade de iniciativa é para ser exercida fora do SUS, ou seja, em paralelo aos serviços públicos de saúde. A iniciativa privada pode concorrer com o SUS, mediante os segmentos (a) da atenção particular tradicional, com contratação pelo interessado do médico ou hospital, e (b) da saúde suplementar, prestada por intermédio de empresas de assistência e seguros em saúde, também numa relação de direito privado.

Dentro do SUS, a participação de serviços privados é estritamente complementar à rede pública. O constituinte reconheceu que as estruturas públicas poderiam ser insuficientes para acolher toda a demanda do SUS e, por esse motivo, admitiu que o Poder Público pudesse complementar a sua rede própria com serviços privados contratados ou conveniados. Ou seja, instituições particulares podem participar do SUS quando indispensável para satisfazer as necessidades sociais. Essa participação será em caráter precário, pois a prestação do serviço público de saúde é responsabilidade direta do Estado. O legislador ordinário federal percebeu, com rigor técnico, a decisão constitucional, tendo regulado no art. 24 da Lei n. 8.080/90 que:

Art. 24. Quando as suas disponibilidades forem insuficientes para garantir a cobertura assistencial à população de uma determinada área, o Sistema Único de Saúde (SUS) poderá recorrer aos serviços ofertados pela iniciativa privada.

Parágrafo único. A participação complementar dos serviços privados será formalizada mediante contrato ou convênio, observadas, a respeito, as normas de direito público.

Há, portanto, dois universos bem distintos de atuação em saúde: o SUS e o privado. No SUS, o papel da iniciativa privada é acessório, coadjuvante, sempre por decisão do próprio Estado. Não há um direito subjetivo do particular a integrar o SUS. Decorre, daí, uma suposta confusão pelos formuladores da proposta da fundação estatal. A área da saúde não é de atuação exclusiva do Poder Público; porém, o SUS é essencialmente estatal. Os dois planos (SUS e não-SUS) não se misturam, exceto quando o Poder Público exerce o controle e a fiscalização das ações privadas (não-SUS), em regra por meio da vigilância sanitária e epidemiológica.

O Poder Público, no SUS, é sempre um prestador de serviço público. Não há outra possibilidade. E, fora do SUS, não há autorização para atuar. Todo esforço estatal em saúde deve ser realizado dentro do SUS. E será, evidentemente, parte da prestação do serviço público de saúde.

Afigura-se manifestamente sem sentido jurídico a proposta de instituir uma pessoa estatal para prestar serviços ao SUS como se iniciativa privada 
fosse. Seria o Estado vendendo serviços ao Estado, simulando que é uma instituição privada, a qual sequer deveria compor o SUS (frise-se, só está no SUS precariamente).

A formulação constitucional, densificada pela Lei n. 8.080/90, é muito clara: toda estrutura pública de saúde é parte do $S U S^{(10)}$. E, não seria necessário dizer, presta serviço público de saúde.

Mas não é só. A fundação estatal - na hipótese estudada - será mantida com recursos públicos. Ainda que percebidos mediante um "contrato de gestão", os recursos não perderão sua natureza pública. São verbas provenientes do Fundo de Saúde.

Em suma, a fundação estatal prestará serviços públicos e será mantida com recursos públicos. Sua natureza, à luz da jurisprudência do Supremo Tribunal Federal, é de fundação de direito público, adstrita ao regime administrativo constitucional. Não será, portanto, constitucionalmente adequada a instituição de uma entidade estatal, no regime de direito privado, para atuar como prestadora de serviços dentro do SUS.

Com relação ao segundo "nicho de atuação" apontado para as fundações estatais - oferta de recursos humanos a Municípios que não gozam de condições de estabelecer uma carreira motivadora - também identificamos dificuldades de reconhecer tal atividade como uma atividade econômica livre à iniciativa privada. Embora convencidos da criatividade da medida e do esforço em criar alternativas para a dramática dificuldade em manter profissionais de saúde em pequenas cidades ou locais de mais difícil acesso, identificamos incompatibilidade entre o modelo da fundação estatal e a natureza da atividade realizada.

A exemplo do que referido quanto ao outro modelo de operação da fundação estatal, também nesta hipótese estar-se-á diante de um serviço público, mantido por recursos públicos. O Estado, por intermédio da fundação estatal, estará fornecendo recursos humanos inerentes à prestação do serviço público de saúde, ou seja, cuidará de garantir um dos insumos essenciais do atendimento à população. Ademais, ainda que a manutenção da entidade decorra de pagamentos efetuados pelo Município, não se poderá desconsiderar que tais recursos possuem natureza pública, do SUS. Em suma, a atividade vislumbrada será típica do SUS, ainda que desdobrada em função-meio.

(10) Art. 4º $O$ conjunto de ações e serviços de saúde, prestados por órgãos e instituições públicas federais, estaduais e municipais, da Administração direta e indireta e das fundações mantidas pelo Poder Público, constitui o Sistema Único de Saúde (SUS). § 1 oㅗstão incluídas no disposto neste artigo as instituições públicas federais, estaduais e municipais de controle de qualidade, pesquisa e produção de insumos, medicamentos, inclusive de sangue e hemoderivados, e de equipamentos para saúde. 
Por esses aspectos, nossa conclusão é pela impossibilidade jurídica de criação e manutenção de fundações estatais de direito privado para as finalidades indicadas, relacionadas à prestação de serviços públicos no SUS. Essas ações devem ser realizadas pelo Poder Público, diretamente, ou por autarquias, ainda que em regime especial.

Do modo como formulada a proposta, o regime jurídico que se pretende adotar parece propiciar apenas riscos à Administração Pública e, em consequência, à sociedade. Com efeito, a defesa de um regime administrativo "mínimo" parece estar diretamente ligada a uma perspectiva de afastar alguns dos preceitos que limitam e protegem o gasto público, principalmente a obrigação de criação de cargos por lei, a limitação de remuneração de pessoal mediante "tetos", a vinculação da política salarial a um plano de carreiras, a aplicação da Lei de Responsabilidade Fiscal e a exigência de licitações.

A instituição das fundações estatais, portanto, enfraquecerá o SUS, ao invés de fortalecê-lo.

\section{PROBLEMAS NÃO ENFRENTADOS}

A proposta de agilização da gestão dos serviços públicos de saúde, bem como de garantia de recursos humanos é muito bem-vinda. No entanto, o modelo apresentado afigura-se inadequado, conforme exposto no item precedente. Infelizmente, o projeto traz como elementos que mais se destacam as perspectivas de pagamentos de remuneração acima do teto de vencimentos da administração, gerando quebra de paradigmas de carreira e permitindo que grandes distorções - existentes no passado, inclusive em diversas fundações estatais de direito privado criadas no cenário pré-Constituição de 1988 - voltem a campear.

Por outro lado, não se identifica, nos textos divulgados pelo governo sobre a proposta, preocupação com diversos aspectos que limitam o desenvolvimento do SUS, também na área de gestão de pessoal. São desafios abertos: o comprometimento dos servidores (mormente médicos) com a eficiência do serviço e o fim do uso das estruturas públicas de saúde para alocação de dirigentes escolhidos por mera indicação política.

$\mathrm{Na}$ verdade, as fundações estatais - tais como formuladas - surgem como um campo propício para o agravamento dessas distorções, na medida em que criarão novos cargos sem controle legislativo, com patamares remuneratórios acima daqueles praticados pela administração pública. E, ademais, com reduzidos mecanismos de controle ${ }^{(11)}$. A proposta, nesse particular, também acena contra o princípio da moralidade administrativa.

(11) A proposta do governo prevê que a fundação estatal federal não participará: do Sistema Integrado de Administração de Recursos Humanos (SIAPE); do Sistema de Cadastramento Unificado 


\section{ALTERNATIVAS}

A prestação dos serviços públicos de saúde é atividade essencialmente estatal e, portanto, deve ser desenvolvida pelo Poder Público, ainda que de forma descentralizada. Essa descentralização deve ser implementada dentro dos parâmetros do direito público. $O$ direito brasileiro possui ferramentas aptas a esse desiderato, não sendo necessário desconstruir importantes conquistas que garantem maior segurança ao patrimônio público e social.

Referimo-nos, em especial, às autarquias. De origem remota, essa espécie de entidade pública vem conhecendo regramentos jurídicos especiais que conferem ao legislador várias possibilidades de dotá-las de instrumentos de eficiência e eficácia. Ainda na década passada foram criadas as agências reguladoras de determinadas atividades econômicas ${ }^{(12)}$, espécie de autarquias especiais que, dotadas de patrimônio próprio, carreira específica e corpo diretivo estável, estabeleceram um novo patamar na administração pública. Muito embora as atividades de regulação e de prestação de serviços públicos sejam bem distintas, o precedente das agências é relevante para demonstrar as possibilidades do direito administrativo.

O Poder Público deveria formular um modelo específico de autarquias de saúde, dotadas de patrimônio e planos de carreira próprios, e aptas a utilizar as ferramentas consagradas no § $8^{\circ}$, do art. 37, da Constituição:

$\S 8^{\circ} A$ autonomia gerencial, orçamentária e financeira dos órgãos e entidades da administração direta e indireta poderá ser ampliada mediante contrato, a ser firmado entre seus administradores e o poder público, que tenha por objeto a fixação de metas de desempenho para o órgão ou entidade, cabendo à lei dispor sobre:

I - o prazo de duração do contrato;

II - os controles e critérios de avaliação de desempenho, direitos, obrigações e responsabilidade dos dirigentes;

III - a remuneração do pessoal.

Essas autarquias assemelhar-se-iam às fundações estatais nos seguintes aspectos: instituição pelo Poder Público, integração à administração

de Fornecedores (SICAF), do Sistema de Administração de Serviços Gerais (SIASG), do Sistema de Informações Organizacionais do Governo Federal (SIORG), do Sistema Integrado de Administração Financeira (SIAFI) e do Sistema Integrado de Dados Orçamentários (SIDOR). Todos esses sistemas são importantíssimas ferramentas de controle, permitindo ao Tribunal de Contas, ao Congresso Nacional e ao Ministério Público a consulta on-line dos registros da gestão pública.

(12) São exemplos: Agência Nacional de Telecomunicações (ANATEL), criada pela Lei n. 9.472/97; Agência Nacional de Energia Elétrica (ANEEL), estabelecida pela Lei n. 9.427/96; Agência Nacional de Vigilância Sanitária (ANVISA), instituída pela Lei n. 9.782/99; Agência Nacional de Saúde Suplementar (ANS), organizada pela Lei n. 9.961/2000, dentre outras. 
indireta, patrimônio e receitas próprios, autonomia gerencial, orçamentária e financeira (compondo o orçamento público do ente federativo respectivo, mas com capacidade para auferir rendas, receber doações e ter dívida ativa), contratação de pessoal pelo regime da CLT, mediante concurso público, sem reconhecimento de estabilidade.

Entretanto, submeter-se-iam à licitação, ao teto remuneratório da administração pública (podendo a lei, à luz do disposto no inciso III, do $\S 8^{\circ}$, do art. 37, da Constituição, determinar a aplicação direta do teto previsto no inciso XI, do mesmo art. 37, equivalente aos subsídios dos Ministros do Supremo Tribunal Federal) e aos sistemas de controles administrativos da gestão pública. Aliás, essas medidas são indispensáveis sob o prisma constitucional e sua supressão do regime das fundações estatais de direito privado macula a legitimidade da proposta governamental.

Nada impede, outrossim, que a lei, além de estabelecer mandatos, imponha regras para a seleção de dirigentes, privilegiando profissionais da carreira (por exemplo, garantindo-lhes cotas de cargos diretivos) e exigindo que toda nomeação seja feita em ato administrativo fundamentado, do qual conste a motivação da escolha e o currículo profissional do escolhido. Essas, aliás, são medidas que podem ser contempladas em qualquer modelo administrativo - inclusive administração direta - e representaria o alcance de um patamar superior no cumprimento dos deveres de transparência e fundamentação de atos administrativos. Afigura-se incompatível com o Estado democrático e republicano que cargos públicos sejam ocupados sem que à sociedade sejam justificados os motivos da escolha e revelados os atributos profissionais do nomeado. É inconcebível que o rico universo de ferramentas eletrônicas da informação não seja utilizado para trazer à luz o processo de seleção e escolha de exercentes de cargos de direção e assessoramento na administração pública.

Da mesma forma, nas autarquias de saúde poderiam ser estabelecidos sistemas de gratificação aos profissionais da instituição com base no resultado, na dedicação e no rendimento global da unidade, mediante pactuações e avaliações transparentes (inciso III, do $\S 8^{\circ}$, do art. 37, da Constituição).

Ambos modelos (fundação estatal e autarquia especial em saúde) não diferem quanto às perspectivas de permitirem maior autonomia administrativa e financeira na gestão do serviço público. Todavia, a autarquia resguardaria princípios administrativos de proteção do patrimônio público e social que estão sendo sacrificados na proposta da fundação estatal. Ademais, as autarquias especiais em saúde são a única espécie efetivamente compatível com o desenho constitucional do Sistema Único de Saúde, dada a natureza dos serviços prestados.

Por fim, anote-se que as autarquias podem ser adotadas para desenvolver as duas funções acima estudadas: gestão de serviços específicos de saúde e estruturação de carreiras estaduais de profissionais. 


\section{CONSIDERAÇÕES FINAIS}

A proposta governamental de instituição de fundações estatais em saúde revela aspectos positivos e negativos.

Devemos saudar a iniciativa de se buscar a retomada pelo Poder Público do exercício de funções e serviços que foram indevidamente repassados ou assumidos pela iniciativa privada no Sistema Único de Saúde. Da mesma forma, é positiva a discussão com a sociedade de novos modelos para superação de alguns problemas graves e crônicos da gestão pública em saúde.

Entretanto, o modelo escolhido - instituição de pessoa jurídica estatal de direito privado - não se afigura compatível com o desenho constitucional. A roupagem de direito privado será um artifício que não se coaduna com a verdadeira função que lhe será atribuída: prestar serviço público. A jurisprudência do Supremo Tribunal Federal é consolidada nesse particular.

Por outro lado, o regime jurídico administrativo "mínimo" que se intenta implementar traz riscos ao patrimônio público, pois permitirá ilimitada remuneração de pessoal, exagerada flexibilização das licitações públicas e supressão de diversos sistemas de controles administrativos. Haverá, também, perda de transparência.

Finalmente, lamenta-se que diversos problemas da gestão permaneçam inatacados, principalmente os relacionados à eficiência e ao tratamento isonômico dos recursos humanos, que devem ser incentivados, avaliados e premiados, conforme seu esforço e envolvimento, especialmente nas hipóteses de dedicação exclusiva ao SUS. A proposta governamental parece formulada para acomodar interesses de alguns setores, e não representa uma novidade relevante em relação aos exemplos negativos do passado, mormente quando se analisa as graves distorções que acometiam as fundações públicas de direito privado que existiam no regime jurídico anterior à Constituição de 1988.

\section{REFERÊNCIAS BIBLIOGRÁFICAS}

AITH, Fernando. Curso de direito sanitário: a proteção do direito à saúde no Brasil. São Paulo: Quartier Latin, 2007.

BRASIL. Ministério do Planejamento, Orçamento e Gestão. Projeto Fundação Estatal: principais aspectos. Brasília: MP, 2007.

BRASIL. Secretaria de Gestão do Ministério do Planejamento, Orçamento e Gestão. Discursos e Palestras. In: Seminário Aspectos Jurídicos da Fundação Estatal. 2007. Brasília/DF. 
DALLARI, Sueli Gandolfi. O conceito constitucional de relevância pública. Brasília: Organização Panamericana de Saúde, 1992.

WEICHERT, Marlon Alberto. A saúde como serviço de relevância pública e a ação civil pública em sua defesa. In: ROCHA, João Carlos de Carvalho et al. (Orgs.). Ação civil pública - 20 anos da Lei n. 7.347/85. Belo Horizonte: Del Rey, 2005. p. 507-531.

Saúde e Federação na Constituição Brasileira. Rio de Janeiro: Lumen Juris, 2004. 